\title{
Hypoglycaemic Reactions in 172 Type 1 (Insulin-Dependent) Diabetic Patients
}

\author{
C. Goldgewicht ${ }^{1}$, G. Slama ${ }^{1}$, L. Papoz ${ }^{2}$ and G. Tchobroutsky ${ }^{1}$ \\ ${ }^{1}$ Diabetes Unit, University Pierre et Marie Curie, Hôtel-Dieu Hospital and ${ }^{2}$ Unité de Recherches Statistiques INSERM, Paris, France
}

\begin{abstract}
Summary. The aim of this study was to discover the frequency, severity and causes of hypoglycaemic reactions in Type 1 (insulin-dependent) diabetes. One hundred and seventy-two outpatients answered a questionnaire which also inquired about their feelings, opinions and fears with respect to insulin reactions. Hypoglycaemic reactions were common: a mild episode occurred at least once a month in $58 \%$ of patients, and at least one severe reaction (defined by the need of assistance) during the past year was described by $26 \%$. Both were positively related to the duration of the disease. However, the occurrence of mild and severe attacks was not related. In addition, patients prone to mild hypoglycaemia seem to be somewhat different from patients prone to severe attacks in their attitudes towards the disease. For example, mild reactions are more fre-
\end{abstract}

quent in patients devoted to 'perfect' control, whereas severe episodes were observed more frequently in those who did not think that controlling diabetes is a difficult task. The social consequences of any reaction, even mild, were important in $30 \%$ of the patients. Twenty-one percent of the patients said that the short-term risks of a hypoglycaemic reaction, even if correctly treated, were high and $6 \%$ said that the fear of having a reaction was unbearable. In addition to rational explanations, emotional factors were given as a cause of hypoglycaemia (14\%), but $11 \%$ of cases felt that attacks occured without any obvious reason in spite of correct management.

Key words: Hypoglycaemia, Type 1 diabetes, diabetes management.
Information concerning the frequency and severity of hypoglycaemic reactions in Type 1 (insulin-dependent) diabetic patients is very scarce. Little data are available on the number of deaths presumed or actually due to hypoglycaemia [1-4].

Malins [5] questioned 100 patients with diabetes of varying duration who were a random sample of those taking insulin. Twenty-four had lost consciousness at least once and 65 had experienced minor attacks short of losing consciousness. Only 11 had never had a hypoglycaemic attack. Major reactions, resulting in coma, were twice as common in men as in women and more frequent in the young. Such major attacks occurred at least once a year in six patients.

Paz-Guevara et al., in a series of 73 insulin-treated juvenile diabetic patient, who had survived for at least 40 years and were followed up in the Joslin Clinic, stated that: "insulin-induced hypoglycaemia was reported by all but two patients" [2]. Indeed, as emphasized by Tattersall and Gale [6], there is little reliable information on the frequency of hypoglycaemia in patients receiving conventional insulin therapy and monitored by urine tests. With the increasing development of home blood glucose monitoring, more studies will probably be carried out in this field [7]. In a previous study, we showed that about $30 \%$ of Type 1 diabetic patients followed up either by diabetologists or by general practitioners, experienced a 'severe' hypoglycaemic reaction at least once a year [8]. 'Severe' was defined by coma, hospitalization, glucagon injection or the need for external assistance.

In the present study, we report an analysis of the experience and feelings of 172 adult Type 1 diabetic patients. The aim of the study was to find out the frequency, severity and causes of hypoglycaemic reactions and to know the feelings and fears of the patients.

\section{Patients and Methods}

All Type 1 diabetic patients (97 women and $94 \mathrm{men}$ ), who had attended our clinic during a 1 month period (March-April 1979) were enrolled in this study: all agreed to participate. The patients were requested to fill out a questionnaire at their leisure at home, and add any comments if desired. An explanatory letter accompanied the questionnaire (which can be obtained from the authors on request). Questions concerned socio-demographic data, history of the disease 
Table 1. Clinical data of 172 insulin-treated diabetic patients who completed the study

\begin{tabular}{lc}
\hline & Patients $(n=172)$ \\
\hline Age (years) & $49 \pm 17(15-86)$ \\
Duration of diabetes (years) & $14 \pm 9(1-52)$ \\
Duration of insulin therapy (years) & $10 \pm 9(1-52)$ \\
Body mass index & $35 \pm 5(21-53)$ \\
Number of examinations per year & $3 \pm 2(1-20)$ \\
Duration of follow-up (years) & $5 \pm 4(1-20)$ \\
Number of insulin injections daily & \\
1 & $26 \%$ \\
2 & $57 \%$ \\
3 & $17 \%$ \\
Profession & \\
Workers & $31 \%$ \\
Employees & $21 \%$ \\
Retired & $22 \%$ \\
No profession & $20 \%$ \\
Managers & $5 \%$ \\
No answer & $1 \%$ \\
\hline
\end{tabular}

Values are expressed as mean \pm SD or percentages. Ranges are given in parentheses.

a Body mass index [19] was calculated by the formula:

$100\left(\log \frac{\text { weight }(\mathrm{kg})}{\text { height }(\mathrm{m})}-\mathrm{l}\right)$

Table 2. Percentage of diabetic patients who experienced hypoglycaemic reactions

\begin{tabular}{llll}
\hline & \multicolumn{3}{l}{ Hypoglycaemic reactions } \\
\cline { 2 - 4 } & $\begin{array}{l}\text { Mild } \\
\text { (per } \\
\text { month) }\end{array}$ & $\begin{array}{l}\text { Severe } \\
\text { (within last } \\
\text { year) }\end{array}$ & $\begin{array}{l}\text { Severe } \\
\text { (within last } \\
\text { 5 years) }\end{array}$ \\
\hline No answer & 16 & 7 & 10 \\
No reaction & 26 & 67 & 48 \\
One or more & 58 & 26 & 42 \\
1 & 11 & 17 & 10 \\
$2-5$ & 28 & 7 & 24 \\
$6-10$ & 9 & 1 & 5 \\
$>10$ & 10 & 1 & 3 \\
\hline
\end{tabular}

All figures are percentages of the 172 subjects who returned the questionnaire

and its management, including number of daily injections and number of visits to the general practitioner and/or the diabetologist. In particular, questions were aimed at gathering information on the number of hypoglycaemic reactions per week, month or year and their severity. 'Severe' reactions were defined as all insulin reactions leading to hospitalization or the need of external help.

All other reactions were classified as 'mild'. We also enquired about symptoms preceding and accompanying hypoglycaemic episodes. Other items dealt with the reported causes of reactions; these involved questions about the effects of divided daily injections, the quality of control, the use of sticks (Dextrostix) for blood glucose home monitoring, information about urine analysis and the search for good control. In addition, we enquired about the estimated danger of hypoglycaemic reactions and attitudes towards a chronic elevated glucose level.

Statistical analysis was carried out using the $\chi^{2}$ test, the Student's $\mathrm{t}$-test, analysis of variance and Pearson's correlation coefficient. Results are expressed as mean \pm SD or as percentages.
Table 3. Relationship between the frequency of hypoglycaemic reactions and other parameters

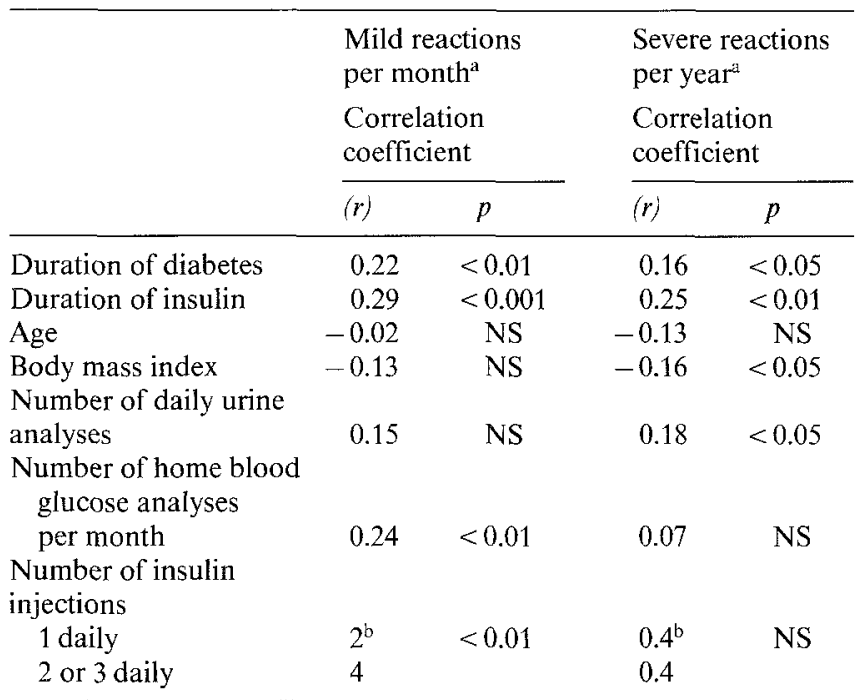

a The correlation coefficient $(r)$ between the frequencies of mild and severe reactions is 0.15 (NS); ${ }^{b}$ average number of reactions. The $p$ value results from a Student's t-test between the two groups

$\mathrm{NS}=$ not significant

\section{Results}

One hundred and seventy-two of the 191 patients (90\%) returned the questionnaire. The 19 who did not answer the questionnaire were compared for 10 parameters describing the history of the disease which were available in the clinical records. Two significant differences were found: the non-responding subjects were on the average younger than the others (mean $\pm S D$ age; $40 \pm 16$ versus $49 \pm 17$ years, $p<0.05$ ), and fewer women answered than men $(86 \%$ versus $95 \%, p<0.05)$. The group studied (Table 1) corresponds very closely to the overall population of diabetic patients who attend our clinic regularly, and who have been reported previously $[8,9]$.

\section{Perceived Level of Self-care}

It appears that the great majority of patients think they do their best to improve control (87\%), comply with the diet $(72 \%)$ and perform regular urine analyses (84\%). Only one out of three used blood glucose home monitoring at least once a month and one out of ten at least once a week (Spring 1979). Of those believing they did their best to obtain control, only $70 \%$ were actually satisfied with the results they obtained.

\section{Frequency of Hypoglycaemic Reactions}

Table 2 shows that $58 \%$ of the patients experienced at least one mild hypoglycaemic reaction per month, $26 \%$ at least one severe episode during the past year, and $42 \%$ during the past 5 years. Twenty-eight percent of the 
patients had been hospitalized at least once for a hypoglycaemic coma since the onset of their diabetes.

We have correlated the frequency of hypoglycaemic reactions of both kinds with the quantitative parameters describing the history of the disease and its management (Table 3). Mild hypoglycaemic reactions were observed more often in patients with the longest duration of diabetes, the longest insulin therapy, in those performing home blood glucose tests more frequently, and in those receiving two or three insulin injections a day.

This point has to be contrasted with the fact that mild hypoglycaemia was more often reported by subjects unsatisfied with the level of their control, and by those who understood that they had made mistakes or were neglectful. The number of severe hypoglycaemic reactions was also positively related to the duration of the disease and to the duration of insulin therapy, but not to age. They were more frequent in thin subjects. A positive significant correlation was found with the number of daily urine analyses $(r=0.18, p<0.05)$. This relationship was not found with mild reactions $(r=0.15$, NS). However, the tendency is similar and the two correlation coefficients are not statistically different.

\section{Causes, Signs and Consequences of Hypoglycaemia}

Of reasons for hypoglycaemia reported by the subjects, $90 \%$ of the questionnaires mentioned the well-recognized causes as 'too much insulin', 'meals too small', and 'exercise without precautions'. They also emphasized the difficulty of simultaneously managing their doses of insulin and diet according to the variations of every-day life and exercise. But other reasons were also reported: general carelessness (11\%), emotions $(14 \%)$, and social problems (6\%). For some subjects (11\%), hypoglycaemia still occurs without any apparent explanation despite careful attention to insulin dosage and diet. The patients who rarely suffered from severe reactions were those who understood why they had attacks and always had a rational explanation for them. The patients who said that hypoglycaemic reactions are not related to errors in food intake, exercise or insulin dosages had more reactions, both severe and mild.

Eighty-two patients had been treated at some time with multiple daily injections of insulin. About half of them $(54 \%)$ had the feeling that changing from one to two or three injections a day diminished $(34 \%)$ or did not modifiy (20\%) the frequency of hypoglycaemia. For the others $(46 \%)$, the change in therapy was associated with an increased number of reactions.

Symptoms as spontaneously described by the patients are listed in Table 4. Some subjects claimed to be unaware of an impending attack; never $(3 \%)$ or occasionally $(16 \%)$. The five most reported symptoms were sweating $(49 \%)$, tremor $(32 \%)$, blurred or double vision $(29 \%)$, weakness $(28 \%)$ and hunger $(25 \%)$. The symptoms on which relatives rely for early diagnosis of hypoglycaemia were also mentioned. These were most
Table 4. Symptoms of hypoglycaemic reactions in 172 type 1 Diabetic patients

\begin{tabular}{ll}
\hline Symptoms & $\begin{array}{l}\text { Percentage } \\
\text { of patients } \\
\text { reporting } \\
\text { symptom }\end{array}$ \\
& 49 \\
& 32 \\
Sweating & 29 \\
Tremor & 28 \\
Blurred or double vision & 25 \\
Weakness & 13 \\
Hunger & 13 \\
Mind confusion & 11 \\
Vertigo & 10 \\
Odd behaviour & 10 \\
Paresthesia around the lips and tongue & 9 \\
Anxiety & 9 \\
Cold feeling & 8 \\
Incoordination & 7 \\
Fear of losing consciousness & 6 \\
Slurred speech & 5 \\
Palpitations & 4 \\
Nausea & 2 \\
Headache & 2 \\
Intense anxiety & 1 \\
Stupor & 0.6 \\
Vomiting & 0.6 \\
Thirst & 3 \\
Sensation of well-being & \\
No symptoms & \\
\hline &
\end{tabular}

commonly pallor (29\% of the questionnaires) and sweating (21\%). In 27 cases, the family did not notice any sign before coma itself. Anxiety about the possible short-term consequences of severe hypoglycaemia, even if rapidly treated, was expressed by $27 \%$ of the subjects. Reasons were not given and the danger was related to the feeling of an 'unbearable' handicap. Diabetic subjects over 60 years mainly fear hypoglycaemia because of the possible long-term consequences. Thirty-eight percent of the diabetic patients answered that they considered hypoglycaemic reactions to be dangerous in the long term, but $55 \%$ also feared the possible consequences of chronic high blood glucose levels: 7\% did not respond to this question.

\section{Discussion}

The possibility of a slight bias in our results cannot be excluded since $10 \%$ of the subjects did not return the questionnaire in spite of a letter of recall. But only rare events can be significantly affected by such a low percentage of non-responders. The main findings resulting from the analysis would not be significantly influenced by the missing responses. Moreover, the remaining 172 subjects constitute a typical sample of insulin-treated out-patients who are being followed up at the HotelDieu clinic $[8,9]$. Most of them $(87 \%)$ were convinced that they made great efforts to achieve good control; about two out of three qualified themselves as well-con- 
trolled. Those patients who considered themselves wellcontrolled had more frequent episodes of both mild and severe hypoglycaemia. Similar observations were also found in another sample of out-patients in our unit [8] and in a comparable group of insulin-treated patients followed-up mainly by general practitioners [8] whose diabetes was less well-controlled and whose everyday life was more disabled than that of the Hotel-Dieu clinic patients. Very few data can be found in the literature concerning hypoglycaemia. Death rates range from $0.23 \%$ to $5 \%$ [1-4]. According to Malins [5] six patients out of 100 experienced at least one coma a year. Our definition of 'severe' hypoglycaemic reactions is broad, including the need for assistance. No figures are available for mild reactions. The frequency of hypoglycaemic reactions in insulin-treated diabetic patients is probably grossly underestimated, perhaps because the patients have a curious tendency to forget or deliberately minimize it' [5].

Another striking result of this study is that hypoglycaemia is stressed by the patients as a risk handicapping their everyday life. This is consistent with Malin's remarks: "patients who have to take insulin nearly all agree that their greatest problem is hypoglycaemia. Those of us who treat diabetes would certainly agree that our own dislike of insulin, if we had to use it on ourselves, would be related to the fear of such attacks" [5]. Consequently, it may well be that the doctor's and the patients' interpretation of 'severe' and 'mild' hypoglycaemia are not always similar. Thirty percent of the patients called 'severe' a reaction that could be socially disturbing, for instance, dizziness or slurred speech occurring at a critical time. However, on the basis of our clinical definitions, mild and severe reactions were not statistically correlated. Thus, some subjects appeared to be prone to severe attacks, while others are subject mainly to mild reactions. This study also shows that a difference lies in particular in the number of home blood glucose tests, which is positively related to mild reactions, but not to severe ones. In contrast, the number of urine tests is related to both kinds of reactions. A possible explanation of these relationships is that subjects who used only urine tests (Spring 1979) may have misleading results; subjects using home blood glucose monitoring were likely to be better educated, and perhaps the quest for a more perfect blood glucose control leads to an increased frequency of mild reactions. This is consistent with the feeling of dissatisfaction about their control reported by subjects suffering from mild reactions. The increase of frequency of both types of reactions with the duration of the disease can be explained by the increasing severity of diabetes since residual insulin secretion, as estimated by C-peptide assays, decreases with time [10]. The finding that thinner patients had more severe reactions is in agreement with the fact that adiposity diminishes insulin sensitivity [11].

Another important aspect is the general feeling, expressed by nine subjects out of ten, that they are over- whelmed with all the factors to be taken into account at any time to avoid both hyper- and hypoglycaemia. In some cases, hypoglycaemia is perceived as an unfair punishment in spite of taking adequate precautions against it. It must be noted that emotional factors were reported by $14 \%$ of the subjects as a cause of hypoglycaemia, an observation which is in apparent contradiction with the well-documented hyperglycaemic effect of catecholamines [12]. However, similar findings have been reported by other authors [13, 15-16].

In discussing symptoms, pallor, a very well-known warning sign, should probably be better taught to the family. A recent study by Sommerville et al. [17] finds results similar to those of this study except that pallor is not mentioned among the four main signs noted by relatives. In a previous work [18], patients answers were compared with the signs mentioned in text-books of diabetes: none of them included all the signs together. It may therefore be of interest to submit the list of symptoms to insulin-treated patients for their education.

In this study, we have attempted to analyse subjective data as objectively as possible. Though it is not easy, we must bear in mind that knowledge of the actual quality of life of the diabetic is the only way to improve educational methods for diabetic people.

Acknowledgements. We gratefully acknowledge the technical assistance given by Miss E. Lesieux.

\section{References}

1. Marble A (1971) Hypoglycaemia due to insulin. In: Marble A, White P, Bradley RF, Krall LP (eds) Treatment of diabetes mellitus, 11th edn. Lea \& Febiger, Philadelphia, pp 297-301

2. Paz-Guevara AT, Hsu TH, White P (1975) Juvenile diabetes mellitus after forty years. Diabetes $24: 559-565$

3. Lestradet H, Papoz L, Helloin de Menibus C, Levavasseur F, Besse J, Billaud L, Battisteli F, Tric PH, Lestradet F (1981) Longterm study of mortality and vascular complications in juvenile-onset (Type I) diabetes. Diabetes 30: 175-179

4. Tunbridge WMG (1981) Factors contributing to deaths of diabetics under fifty years of age. Lancet 2: 569-572

5. Malins J (ed) (1968) Clinical diabetes mellitus. Eyre\&Spottiswoode, London

6. Tattersall R, Gale E (1981) Patient self-monitoring of blood glucose and refinements of conventional insulin treatment. Am J Med 70: 177-182

7. Tattersall R (1979) Home blood glucose monitoring. Diabetologia $16: 71-74$

8. Basdevant A, Costagliola D, Lanoe JL, Goldgewicht C, Triomphe A, Metz F, Denys H, Eschwege E, Fardeau M, Tchobroutsky G (1982) The risk of diabetic control: a comparison of hospital versus general practice supervision. Diabetologia 22: 309-314

9. Tchobroutsky G G, Charitanski D, Blouquit Y, Papoz L, Soria J, Rosa J (1980) Diabetic control in 102 insulin treated out-patients. Diabetologia 18: 447-452

10. Faber OK, Binder C (1977) C-peptide response to glucagon-test for residual beta-cell function in diabetes mellitus. Diabetes 26 : $605-610$

11. Rabinowitz D, Zierler KL (1962) Forearm metabolism in obesity and its response to intra-arterial insulin. Characterization of insulin resistance and evidence for adaptive hyperinsulinism. J Clin Invest 41: 2173-2181 
12. Christensen NJ (1979) Catecholamines and diabetes mellitus (review article). Diabetologia 16: 211-224

13. Kravitz AR, Isenberg PL, Shore MF, Barnett DM (1973) Emotional factors in diabetes mellitus. In: Marble A, White P, Bradley RF, Krall LP (eds), Treatment of diabetes mellitus, 11th Ed., Lea \& Febiger, Philadelphia, pp 767-782

14. Sussman KE, VandenBergh R (1975) The emotional aspects of diabetes. In: Sussmann KE, Metz RJS (eds) Diabetes mellitus, 4th edn. American Diabetes Association, New York, pp 115-121

15. Hinckle LE, Wolf S (1952) The effects of stressful life situations on the concentration of blood glucose in diabetic and non-diabetic humans. Diabetes 1: 383-392

16. VandenBergh RL, Sussman K, Titus C (1966) Effects of hypnotically induced acute emotional stress on carbohydrate and lipid metabolism in patients with diabetes mellitus. Psychosom Med 28: $382-390$

17. Sommerville JM, McLaren EH, Howie EY (1981) Early warning symptoms of hypoglycaemia in ambulant diabetics. Diabetologia 20: 675 (Abstract)
18. Gin H, Goldgewicht C, Slama G, Tchobroutsky G (1982) Symptômes et dangers des hypoglycémies vus par 272 diabétiques et controntés aux données recueillies dans les traités de diabétologie. Diabète Métab (in press)

19. Schwartz D, Lellouch J, Anguerra FG, Beaumont JL, Lenegre J (1966) Tobacco and other factors in the aetiology of ischaemic heart disease in men. Results of a retrospective survey. J Chron Dis $19: 35-56$

Received: 30 December 1981

and in revised form: 24 August 1982

Professor G. Tchobroutsky

Service de Diabétologie de l'Hôtel-Dieu

1, Place du Parvis de Notre-Dame

F-75 181 Paris Cédex 04

France 